The chapters on preparing to write, writing for publication and grant writing contain useful advice but, overall, the book fails to live up to the promise suggested by the title. There is repetition that gives the impression that the book is a collection of published papers thrown together, rather than a carefully edited combination of previous articles. Sadly, because of the verbose and repetitive nature of the text, the book is unlikely to hold the reader's attention long enough to convey the important messages contained within.

\section{Developing the Wise Doctor: A Resource for Trainers and Trainees in MMC}

D FISH, L DE COSSART

\begin{tabular}{ll}
\hline EXTENT P/H & 221 pages, Paperback \\
PRICE/ISBN & $£ 34.95 \quad 9781853156182$ \\
PUBLISHER & RSM Press (London), 2007 \\
REVIEWER & Mohan Kumar \\
STAR RATING & $* * * *$
\end{tabular}

It is always refreshing to see new viewpoints on the nature and function of medical teaching, such as those advanced in this book. The last few years have seen tremendous changes to postgraduate medical teaching and assessment. While most of these represent good intentions we have to share Fish and de Cossart's nervousness that some changes are overwhelmingly managerial and are at risk of missing the complexity of medical learning. They tell us how, by casual introduction of the new assessment mechanisms and 'Tools of the Trade', we are at risk of missing the forest for the trees.

Fish and de Cossart offer solutions that are coherent and practical, that help build on the new system rather than abandon it. In this thought-provoking work based on their own research, Fish and de Cossart lay out a clear and coherent discourse on the nature of postgraduate teaching and learning. They also dig deep into a wealth of resources already available on the issues of teaching and learning, curriculum and professional development, and the themes of narratives and humanities in the practice of medicine.

Intended for postgraduate doctors involved in teaching and learning in a clinical setting, this paperback is divided into two themes: part one helps to diagnose the 'disease' in postgraduate medical education and part two systematically offers up a cure for its ills.

The authors succinctly capture a summary of elements of clinical practice that can be developed and recorded, the standards that might be aimed for and the ability of current available processes to explore and document them. In doing so, they come up with the overview of what they call the 'invisibles': those elements of practice such as personal qualities, professional judgements, complex decision-making, values and attitudes that are not immediately visible to the clinical supervisor. The authors offer memorable heuristics and resource-based learning that help unravel the invisibles in the bulk of the book.

The ideas presented herein will be the glue that sticks together the fragmented 'Tools of the Trade' to produce a richer, multidimensional teaching and assessment package. This book will be of enormous benefit for teaching and supervision and should be essential reading for anyone engaged in postgraduate medicine as learner, teacher or manager.

\section{Recent Advances in Surgery 30}

IRVING TAYLOR, COLIN JOHNSON

\begin{tabular}{ll}
\hline EXTENT P/H & 200 pages, Paperback \\
PRICE/ISBN & $£ 35.00 \quad 9781853157202$ \\
PUBLISHER & RSM Press (London), 2007 \\
REVIEWER & Alexander Blackmore, Madu Onwudike \\
STAR RATING & $* * * *$
\end{tabular}

The Recent Advances in Surgery series, edited once more by Irving Taylor and Colin Johnson, has now reached its 30th edition and will be familiar to many surgical trainees and consultants. In recent years, the series has been published annually and the book consists of sections dedicated to some of the subspecialities within general surgery; a section entitled 'Surgery in General', which pertains to topics relevant to all practitioners of surgery; and finally a chapter reviewing recent randomised clinical trials. This edition includes sections dedicated to breast, gastrointestinal and vascular surgery. Contributors include both surgical trainees and leading consultants in their respective fields, including a number from overseas and those in other specialties where their expertise relates to the topic under consideration.

The information in the individual chapters is presented in a concise and readable format, with useful summary boxes containing key points. Relevant photographs, imaging and other illustrations are presented, with colour plates included in the section on vascular surgery.

The 'Surgery in General' section contains a thought-provoking chapter on risk management and, among other things, examines how this issue is addressed in a more systematic way by anaesthetists and the airline industry. The chapter on the surgical significance of MRSA is topical but consists largely of personal opinion and lacks a firm evidence-base. We were disappointed with the emphasis given to the role of medical staff's clothing in the dissemination of MRSA while neglecting significance of high bed-occupancy rates prevalent in many NHS institutions. 